\title{
Dificuldades brasileiras no setor de Energia elétrica nos anos de 2014 e 2015: Uma perspectiva da população de Guarus em Campos dos Goytacazes/RJ
}

\author{
Jackeline Hatala Jalles \\ Jonathan Velasco Silva \\ Caio Silva Carneiro \\ DOI - 10.25160/v5i2.d11
}

\section{1 - Introdução}

Um dos principais indicadores de economia forte em países emergentes, a geração de energia, vem passando por diversas dificuldades no Brasil, as quais podem ser observadas principalmente em dois momentos históricos. No início dos anos 2000, durante o governo de Fernando Henrique Cardoso, o país sofreu com um racionamento de energia elétrica, além dos apagões, e atribuiu-se a isso que o setor elétrico sofreu com um crescimento no consumo de energia elétrica que não foi acompanhado pela geração da mesma (BARDELIN, 2004).

Já em 2014 e 2015, o país passou por nova crise energética, principalmente devido à escassez de chuva em regiões como o Sudeste (EBC, 2015) (BRASIL, Câmara dos Deputados, 2015). Com isso, esta crise foi comparada à do governo Fernando Henrique Cardoso e até mesmo foi considerada a pior crise energética da história brasileira.

Para Tolmasquim (2000), além da falta de chuvas num longo período, as informações passadas a respeito dos níveis dos reservatórios demonstravam claramente uma ineficiência de operação dos setores responsáveis por gerirem as reservas de recursos hídricos das usinas geradoras de energia.

Com isso, os reservatórios de água encontravam-se em níveis muito baixos (TELES, 2015) e a solução encontrada no setor elétrico brasileiro foi a utilização das usinas termelétricas. No entanto, o custo de geração deste tipo de energia é bem mais elevado, o que culminou em um aumento nas tarifas energéticas (AMATO, 2015). Com isso, as termelétricas que geravam 16,3\% da energia consumida no país em 2013 passaram a ser responsáveis por um percentual de geração de energia consumida correspondente a 30,13\% em 2014 (NEHER, 2015).

Não bastando a dificuldade na geração de energia elétrica, o país passou por grande instabilidade econômica, que para alguns especialistas trata-se de uma crise e recessão (EXAME, 2015), a qual teria provocado um desequilíbrio no consumo de energia elétrica. 
Segundo o Balanço Energético Nacional (BEN) de 2015, ano base 2014 (EPE, 2015), o setor residencial apresentou em 2014 um crescimento no consumo de eletricidade de 5,7\% comparado ao ano anterior, visto as altas temperaturas em 2014 (SEEG/OC, 2015). Enquanto isso, o setor industrial apresentou uma queda de $2 \%$, indicando que tem passado por dificuldades no Brasil. Esses problemas acabaram afetando a economia dos consumidores residenciais, que em alguns casos passaram a pagar um aumento de 50\% na tarifa de energia elétrica, provocando uma insatisfação popular.

Além desse cenário interno, é notório também o modelo de sociedade posto pelo capitalismo consumista, o qual tem trazido grandes desafios, provocados pelo uso desordenado e intensivo de recursos naturais, sendo evidenciados problemas como a escassez de água e os impactos ambientais na utilização de energia (MCGINNIS; ELIMELECH, 2008).

Para MORAIS (2015), o desenvolvimento socioeconômico aliado a progressos tecnológicos no que tange a geração e transmissão de eletricidade contribuiu para a criação de grandes polos urbanos e industriais. Entretanto, tais progressos não abrangem toda a população ou a atende de modo ineficaz. Nesse quesito, começa-se a considerar, além dos fatores econômicos, uma questão de sustentabilidade, segurança energética, custo social, entre outros fatores, os quais influenciam a matriz energética brasileira.

Tendo em vista os dizeres midiáticos sobre a crise, as discussões científicas e a literatura consultada, este trabalho busca identificar se houve interferências na economia dos consumidores residenciais e, caso tenha ocorrido, qual é a percepção da população do distrito de Guarus quanto aos motivos que levaram à recente crise na energia elétrica e se alguma atitude foi tomada para contribuir na redução do consumo de energia.

\section{2- Referencial Teórico}

\section{1-Breve Histórico do Sistema Elétrico Brasileiro}

A energia elétrica é um fator primordial no desenvolvimento econômico e social no mundo. Segundo Cruz (1994), a exploração da eletricidade iniciou-se no Brasil concomitantemente com a Europa e os Estados Unidos. Entretanto, o uso da eletricidade teve início no Brasil no fim do século XIX no período conhecido como da República, quando foi construída, no Rio de Janeiro, a iluminação elétrica da estação central da Estrada de ferro de D. Pedro II. 
A primeira usina hidrelétrica do país a entrar em operação foi a de Ribeirão do Inferno, afluente do rio Jequitinhonha, em Portão de Ferro, na cidade de Diamantina (MG), por iniciativa do engenheiro Arthur Thiré. A usina tinha uma queda de 5 metros de altura e sua geração utilizava 2 dínamos acionados por roda d'água de madeira. A energia produzida era usada a $2 \mathrm{~km}$ de distância, através de uma linha de transmissão considerada a maior linha de transmissão já construída.

Devido à implementação de sistemas de iluminação elétrica e início de algumas atividades industriais, entre 1800 e 1900 foi necessária a construção de pequenas usinas de geração elétrica. No entanto, em virtude do alto custo das mesmas, baixo nível de confiabilidade e da extensa geografia brasileira, foi necessária a construção de usinas termelétricas que dominaram o processo de geração até a virada do século (CRUZ, 1994).

Segundo Rodrigues (2013), o início do uso da energia elétrica no Brasil foi limitado a alguns serviços públicos e à atividade fabril. Até o final de 1890, as empresas de energia elétrica eram locais e independentes, demonstrando a inexistência de qualquer campo organizacional do setor no país.

No período compreendido entre 1899 e 1927 chegaram ao Brasil os grupos Light e Amforp, que logo monopolizaram o setor elétrico. No governo de Getúlio Vargas, a geração hidrelétrica destacou-se e neste período foi criado o Conselho Nacional de Águas e Energia Elétrica (Cnaee), enquanto que em 1945, a primeira empresa estatal federal de geração de energia elétrica foi criada, a Companhia Hidroelétrica do São Francisco, Chesf (LORENZO, 2001).

Posteriormente, a construção de usinas hidrelétricas foi impulsionada e foi por meio do Ministério de Minas e Energia (MME) que se chegou no modelo atual do setor elétrico, onde o estado exerce sua função através da Agencia Nacional de Energia Elétrica (Aneel) (LORENZO, 2001).

No que concerne a cidade de Campos dos Goytacazes, há cerca de 133 anos, a mesma tornou-se a primeira cidade da América Latina a ter iluminação pública elétrica. Este pioneirismo deveu-se a uma termelétrica a vapor com potência de $52 \mathrm{KW}$ que acionava 39 lâmpadas. O mecanismo foi inaugurado pelo próprio Imperador Dom Pedro II (URURAU, 2016).

\section{2- Matriz Energética Brasileira}

A matriz elétrica brasileira é predominantemente hidráulica e apresenta uma complemen- 
tação térmica, como pode ser observado no gráfico 1. No entanto, nos últimos dez anos essa complementação tem sido diversificada, sendo composta por diversas fontes de energia como a eólica; gás natural; petróleo e derivados; nuclear; carvão e biomassa; dentre outras que começam a surgir nos dados de geração, que é o caso da energia solar, ainda com uma participação bem modesta.

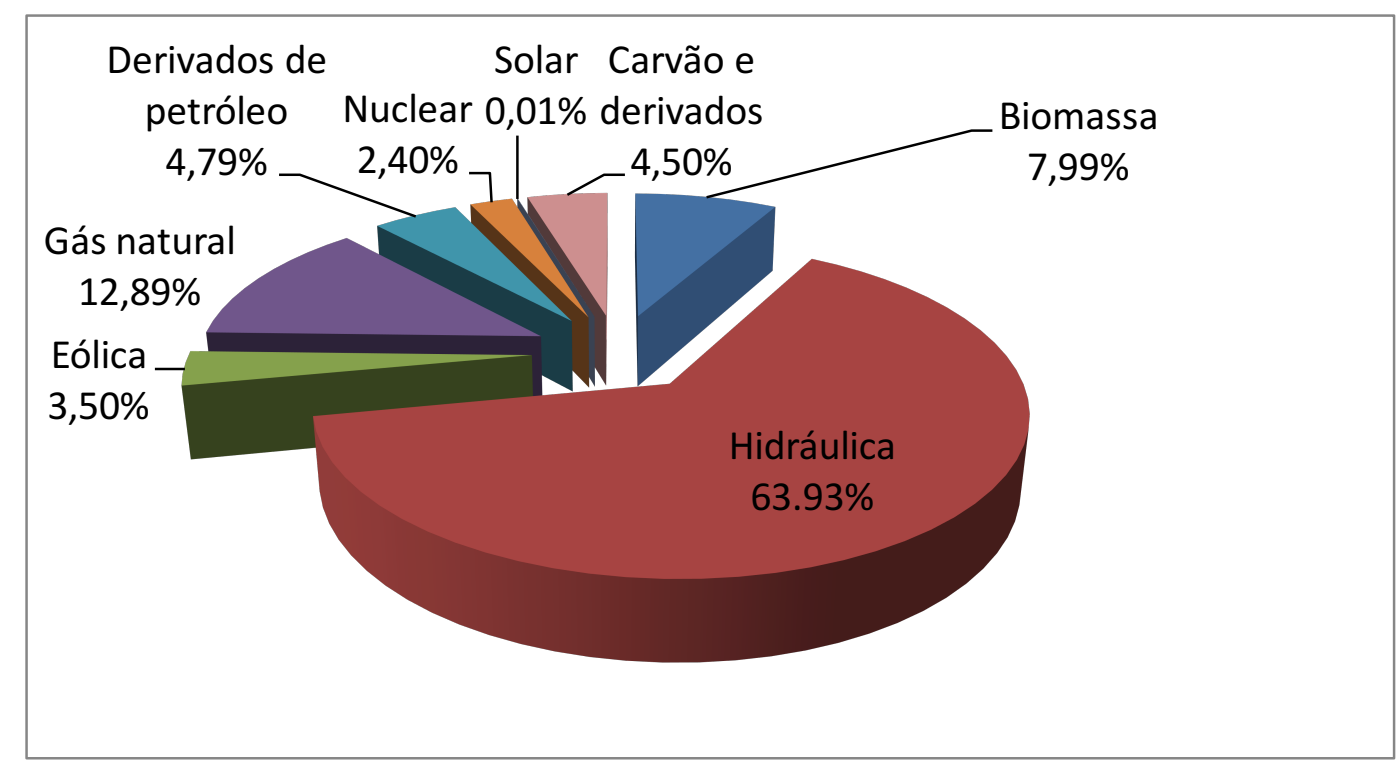

Gráfico 1 - Oferta Interna de Energia Elétrica por Fonte

Fonte: adaptado de BEN 2016

Por ser uma matriz em que a maior fonte é a hidráulica, o Brasil se sobressai no que diz respeito do percentual de energia renovável em sua geração. Porém, essa dependência tem causado alguns transtornos em períodos de secas, que levam a uma baixa nos reservatórios de água.

A partir da crise nos anos de 2000 e 2001 iniciou-se a construção de diversas termelétricas como solução para o problema (ANEEL, 2002). No entanto, isso fez com que o Brasil andasse na contramão da proposta mundial de reduzir as fontes térmicas, principalmente as que utilizam combustíveis não renováveis. Com isso, a partir de 2004 foi lançado o Programa de Incentivo às Fontes Alternativas de Energia Elétrica (Proinfa), através do Decreto $n^{0}$ 5.025, de 2004, com o objetivo de aumentar a participação das fontes renováveis de energia na matriz brasileira.

Em dez anos, as energias renováveis alternativas cresceram 30\%, passando de 2,8\% de toda a oferta de energia interna em 2004 para 4,1\% em 2014. O incentivo às energias renováveis pode ser considerado uma meta do Ministério de Minas, que por meio do Banco Nacional de Desenvolvimento (BNDES), investiu em 285 iniciativas de energias reno- 
váveis no período de 2003 a 2015. Somente na energia eólica, foram mais de R\$ 19 bilhões em financiamento (BRASIL, 2015).

Estudos indicam que o potencial eólico brasileiro é de aproximadamente 60.000 MW, sendo que os melhores potenciais estão nas regiões Norte e Nordeste. Entretanto, a participação da energia eólica na geração de energia elétrica ainda é praticamente desprezível no Brasil, apesar da criação de programas como o Programa Emergencial de Energia Eólica. A energia eólica é proveniente de uma fonte energética inesgotável, visto que utiliza o vento, não emite gases poluentes; o terreno pode ser usado para outros fins, como a agricultura; e ainda reduz a dependência energética do exterior. Em relação aos impactos socioambientais desse tipo de geração de energia, destacam-se os sonoros, os visuais e a possibilidade de interferências eletromagnéticas (ANEEL, 2002).

De acordo com o MME (2015), outra fonte de energia renovável é aquela proveniente de biomassa, isto é, matéria orgânica que pode ser usada na produção de energia. A biomassa tem tido grande importância no consumo final de energia primária do planeta, além de contribuir com boa parte da oferta de energia primária do Brasil, já que o país gera uma grande quantidade de resíduos na produção de madeira, no setor sucroalcooleiro e na agricultura, como é o caso da cana-de-açúcar, e todos esses resíduos podem ser utilizados para gerar energia elétrica.

Em 2014, a oferta total de bioenergia foi de 84,4 milhões de tep (1.640 mil bep/dia), o que corresponde a 27,6\% da matriz energética brasileira (MME, 2015). Isto é, o Brasil tem um território com grande potencial para ser aproveitado, mas devido à relativa baixa eficiência e altos custos de produção e transporte de biomassa, esta fonte de energia ainda não é muito utilizada.

A principal fonte de produção de energia elétrica brasileira são as hidrelétricas, utilizadas desde o século 19. Hoje, o potencial hidrelétrico brasileiro é estimado em cerca de 260 GW e o Brasil possui a maior hidrelétrica do mundo em geração de energia (Usina de Itaipu), a qual tem uma potência instalada de 14 mil MW, o suficiente para suprir 20\% da demanda do sistema interligado brasileiro (BRASIL, 2010).

A hidroeletricidade é a forma de produção de energia elétrica mais eficiente no processo de conversão, ou seja, a energia mecânica do movimento hidráulico é mais bem aproveitado do que qualquer outro processo em que se produza energia elétrica atualmente (EPE, 2007). Entretanto, para a construção de uma hidrelétrica é necessária uma área muito grande, além das preocupações ambientais com o projeto, pois é essencial preservar a biodiversidade local e evitar a formação de microclimas, que podem influenciar na sobrevivência da diversidade biológica. Existe ainda a possibilidade de rompimento de barragens e outros acidentes que podem ocorrer (ANEEL, 2002). 
A energia solar é responsável por diversas fontes de energia. Como fonte primária de energia no planeta, é diretamente responsável pelas dinâmicas do vento, da água, processos vegetais, entre outros. Por isso, a geração de energia elétrica a partir de biomassa, a eólica e a hidráulica são dependentes da luz solar. A radiação solar necessária para a produção de energia elétrica depende das condições climáticas, as quais são favoráveis no território brasileiro, visto sua localização, que faz com que o mesmo receba bastante radiação solar durante todo o ano (VICHI, 2009).

Segundo Afonso (2012), o sistema utilizado na Alemanha, onde era pago uma compensação ao produtor de energia por fontes renováveis, fez com que o país começasse a se destacar na produção de energia solar fotovoltaica conectada à rede, sendo hoje o maior país com essa capacidade, mesmo apresentando menos radiação solar que a região menos ensolarada brasileira.

O Brasil possui inúmeras vantagens naturais e técnicas de industrialização que podem ser aprimoradas para a construção de um sistema de energia fotovoltaica eficiente, com baixo impacto ambiental (AFONSO, 2012). Entretanto, existe a problemática do custo dos equipamentos do sistema fotovoltaico, além de necessitar de grandes áreas para captar energia.

Fonte de energia não renovável, mas com grande importância no cenário mundial na produção de energia, é o petróleo e seus derivados, os quais recebem investimento ininterruptamente e até mesmo causam conflitos entre países. De acordo com Tolmasquim et al. (2007), em 2020 a produção de petróleo no mundo pode atingir 3 milhões de barris por dia.

Contudo, desde a década de 70, o uso do petróleo para gerar energia elétrica tem diminuído, visto que houve um aumento da regulamentação ambiental e competição de fontes de energias alternativas (ANEEL, 2002). Outro motivo para isso é o grande impacto ambiental causado pela queima de combustíveis fósseis para geração de eletricidade, como é feito nas usinas termelétricas, emitindo grande concentração de poluentes, e entre eles, os gases de efeito estufa.

Entre os combustíveis fósseis, o carvão mineral é o mais abundante, e as reservas brasileiras do mesmo estão principalmente no Sul do país. Mesmo assim, seu uso energético não é muito aproveitado no Brasil, pois o grande potencial para gerar eletricidade ainda são as hidrelétricas (BRASIL, 2011).

Dentre as fontes não renováveis, a que mais expandiu foi o gás natural, considerando o período de 2013 a 2014. Isso se deve principalmente ao seu uso maior na geração de energia elétrica (MME, 2015), visto que a escassez de chuvas no Brasil tem provocado pro- 
blemas na geração de eletricidade através das hidrelétricas. Em 2014, o gás natural já representava aproximadamente $13 \%$ da matriz energética nacional.

Outra fonte de energia que o Brasil utiliza é aquela proveniente da fissão do urânio, já que o país possui uma das maiores reservas do mundo desse metal. A primeira usina nuclear brasileira a entrar em operação foi a Angra 1, em 1985, e posteriormente a Angra 2 entrou em atividade. A tendência é que o Brasil aumente sua capacidade de produção deste tipo de energia, principalmente com a construção de Angra 3, apesar de existirem problemas com a disposição dos rejeitos nucleares (BRONZATTI, 2008).

\section{3-Situação atual}

O Brasil apresenta grande disponibilidade de água, a distribuição em diferentes regiões do país é bastante desigual. A situação atual relaciona-se, em termos de escassez hídrica, principalmente com um planejamento inadequado do uso da terra associado ao crescimento econômico: área do Sudeste do Brasil com grande oferta hídrica, por exemplo, é afetada pela falta de água relacionada com a urbanização descontrolada. A disponibilidade de água no Brasil está intimamente ligada ao clima, especialmente, durante os meses de verão. Atrasos no início da estação chuvosa podem afetar a agricultura e a geração de energia; e a ocorrência de enchentes e secas de grande escala tem produzido fortes impactos na economia e na população. (MARENGO, 2010, p 201).

Para Kirchner (2015), a atual crise pode ser pior que a crise que gerou o racionamento em 2001, levando a população a pagar um aumento de até 50\% na tarifa de energia elétrica devido a erros da administração que investiu em termelétricas com alto custo de geração, ao tempo que poderia ter investido em geração com fontes e sistemas mais baratos visto as condições climáticas brasileiras serem favoráveis a outras fontes mais renováveis e baratas.

No início dos anos 2000, o setor elétrico sofreu com um crescimento no consumo de energia elétrica o qual não foi acompanhado pela geração da mesma além do baixo índice de chuvas (BARDELIN, 2004) e em 2015 o país passou por nova crise energética, a qual é comparada à do governo Fernando Henrique Cardoso e considerada a pior crise energética da história brasileira.

Para entender melhor esta crise hídrica brasileira, pode-se observar o que aconteceu 
no sistema Cantareira em São Paulo e sul de Minas Gerais. Segundo O GLOBO (2014), este complexo hídrico, que é formado pelas represas Jaguari, Jacareí, Cachoeira e Atibainha, fornece água para cerca de nove milhões de pessoas. No referido período, precipitou quase metade da média histórica, o que fez com que os reservatórios ficassem no volume morto e comprometessem o abastecimento. A dinâmica social em relação ao consumo d'água alterou-se de tal modo que gerou uma real adaptação da população àquele déficit, passando esta a consumir menos.

A dependência entre água e geração de energia no país é extremamente forte, e com a escassez de chuvas prejudicando o fornecimento do combustível de geração de eletricidade em hidrelétricas, a água, houve um crescimento no uso na geração térmica, bem como um aumento tarifário devido ao maior custo de produção deste tipo de energia.

Os problemas atuais que o Brasil enfrenta com a falta d'água em regiões estratégicas do país, tem levado a população a sofrer com rodízios ou a redução de pressão no fornecimento de água como no caso da cidade de São Paulo (SABESP 2016). Para Barros e Barros (2015) o problema a falta d'água brasileira é reflexo da política de águas do país que até 1940 era regido pelo ministério da agricultura, sendo transferida a responsabilidade para o Ministério de Minas e Energia, num momento em que era priorizado o crescimento industrial e a geração de energia e somente em 1995 as políticas de água passou a ser responsabilidade do Ministério do Meio Ambiente.

Ainda há que se considerar que o brasileiro carrega uma cultura de desperdício muito arraigada na sociedade provocando nesta discussão o desperdício de água e energia, (BARROS e BARROS, 2009).

Assim, é possível notar que o problema da falta de água que tem levado o país a crises no setor de energia elétrica, não é um problema causado unicamente pela falta de chuvas, mas também uma questão social cultural, administrativo por parte do poder público e empresas privadas responsáveis pelos recursos hídricos e energéticos do país.

Num país em desenvolvimento como o Brasil, o consumo de energia per capita ainda é pequeno e não se poderia esperar que medidas de eficiência energética tivessem tanto impacto como na OCDE, já que é indispensável que o consumo de energia cresça para promover o desenvolvimento. No entanto, nada impede que o uso de tecnologias modernas e eficientes seja introduzido logo no início do processo de desenvolvimento, acelerando com isso o uso de tecnologias eficientes. Esse é o chamado efeito leapfrog- 
ging, que se contrapõe ao pensamento de que, para haver desenvolvimento, é preciso que ocorram impactos ambientais Goldemberg (2015).

\section{4- Consumo de energia elétrica no Brasil}

De 2013 para 2014 todas as fontes de energia apresentaram crescimento de oferta. Com a expansão da produção de petróleo, de gás natural e do consumo de energia elétrica na geração termelétrica, o setor energético apresentou um aumento de 5\% no consumo em 2014 (MME, 2015).

Segundo o Balanço Energético Nacional 2015 (BEN 2015), o consumo de energia elétrica no setor residencial corresponde a aproximadamente $21,2 \%$ do consumo total, ficando atrás apenas do setor industrial. Ainda segundo o BEN 2015, o consumo residencial apresentou $5,7 \%$ de aumento em relação ao ano anterior, enquanto o setor industrial teve uma queda de $2,0 \%$.

Para Andrade (2014), a posse de equipamentos eletroeletrônicos, diferentes hábitos de consumo em decorrência da evolução tecnológica, além da própria melhoria de renda, que gera um aumento na capacidade consumidora em geral, são motivos que levam a um aumento do consumo de eletricidade nas residências.

Os dados do Balanço Energético Nacional (2016) mostram que em 2015 o consumo de energia residencial foi responsável por 21,3\% do consumo nacional, perdendo apenas para a indústria, que correspondeu a 31,9\%. De acordo com os dados do Balanço Energético Nacional (2016) o consumo no setor residencial apresentou uma taxa média de crescimento anual de aproximadamente 4,45\% entre 2006 e 2013, em 2014 houve uma queda na taxa de crescimento apresentado um aumento de 1,3\% no consumo com relação a 2013 e em 2015 houve uma queda de 1,3\% com relação a 2014.

O preço da eletricidade, apresenta maiores tarifas no setor residencial, já que tem maior custo de distribuição (MME, 2015). Esses dados afirmam que numa necessidade de economia de energia, a contribuição da população é importante e necessária.

De acordo com Achão (2003), o consumo elétrico no setor residencial pode ser influenciado principalmente por determinados fatores como: acesso inicial ao conforto oferecido pela rede, o que supre uma demanda reprimida; planos assistenciais oferecidos pelo governo que aumentaram o poder aquisitivo de uma parte significativa da sociedade; e a maior tendência de se realizar o lazer no conforto do lar, por questões econômicas, de segurança, além de ser vocação tecnológica. 
Além do apresentado acrescenta-se a resolução normativa N. 547, DE 16 DE ABRIL DE 2013, trouxe para população mais oneração na conta de energia elétrica com a criação de bandeiras tarifárias.

O cenário de escassez, que não se deve apenas a razões climáticas, mas à desorganização regulatória do sistema, especialmente à nova sistemática de leilões e à Medida Provisória 579, convertida na Lei 12.783/2013, levou a que a Aneel passasse a aplicar, a partir de janeiro de 2015, as bandeiras tarifárias. Trata-se de medida que permite o repasse do custo de aquisição de energia térmica pelas distribuidoras para os consumidores no mês subsequente. Janeiro, fevereiro, março e abril de 2015 estão com a bandeira vermelha, o que implica acréscimo na tarifa de $\mathrm{R} \$ 5,50$ por $100 \mathrm{kWh} / \mathrm{mês}$ consumidos. Com a bandeira amarela, o aumento é de $\mathrm{R} \$ 2,50$ por 100 kWh/mês (GUIMARAES 2015).

\section{3- Metodologia}

Foi realizada uma pesquisa de natureza aplicada, abordagem quantitativa e com objetivo descritivo. Em relação aos procedimentos técnicos, a pesquisa assumiu a forma de levantamento, por envolver a interrogação direta das pessoas entrevistadas.

O formulário foi elaborado de acordo com a problemática identificada, o objetivo do trabalho e as informações que se desejava adquirir após pesquisa teórica sobre o assunto. O formulário foi testado durante um mês com o objetivo de verificar se o mesmo estava sendo eficiente e identificar possíveis problemas surgidos durante a aplicação dos formulários. Após a fase de teste foram feitas as mudanças necessárias no mesmo.

A pesquisa foi realizada em diversas localidades de Guarus, no período matinal, e durante um ano. A coleta de dados foi feita pelo próprio autor e foi realizada em cinco bairros, os quais foram escolhidos de acordo com a melhor facilidade de acesso: Parque Alvorada, Jardim Carioca, Parque Santa Helena ou Jardim Guarus, Parque Santo Antônio, Parque Vicente Gonçalves Dias.

Quanto aos domicílios, considerou-se somente os domicílios particulares permanentes ocupados, que são aqueles que, "na data de referência, estavam ocupados por moradores e nos quais foram realizadas as entrevistas" (IBGE, 2010). Além disso, tais domicílios foram escolhidos de modo aleatório dentro dos bairros. 
Tabela 1. Bairros onde foram aplicados os formulários e seus respectivos números de domicílios particulares permanentes ocupados

Bairros analisados no estudo
Número de domicílios particulares permanentes ocupados

\begin{tabular}{cc}
\hline Parque Alvorada & 864 \\
Jardim Carioca & 836 \\
Parque Santa Helena ou Jardim Guarus & 1117 \\
Parque Santo Antônio & 684 \\
Parque Vicente Gonçalves Dias & 2792 \\
População total & $\mathbf{6 2 9 3}$ \\
\hline
\end{tabular}

Fonte: adaptado de BRASIL. Ministério do Planejamento, Orçamento e Gestão.

A partir da Tabela 1, delimitou-se a área de estudo dentro do distrito de Guarus de acordo com a Figura 1.

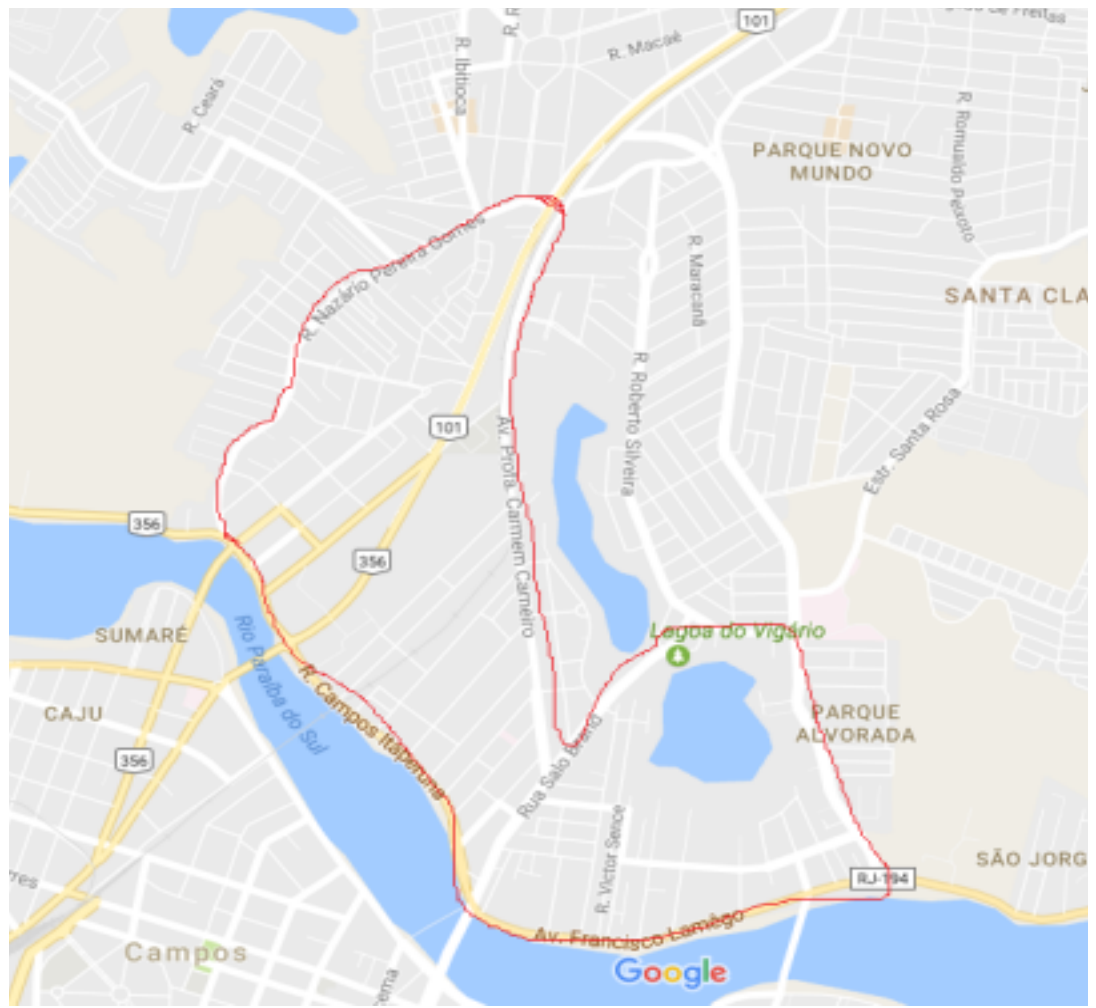

Figura 1. Área de estudo em Guarus

Fonte: adaptado de GOOGLE. 
Após a obtenção da população total que se desejou estudar foi necessário quantificar o número de formulários que deveriam ser aplicados, isto é, o tamanho da amostra.

De acordo com CASTANHEIRA, 2008, população finita é aquela onde o número total de elementos que a forma é conhecida, referindo-se, assim, a um universo limitado. Já população infinita é aquela que possui um número infinito de elementos, os quais não podem ser contados, referindo-se, assim, a um universo não delimitado.

Visto isso, a população estudada pode ser caracterizada como finita e, portanto, calculou-se o tamanho da amostra e concluiu-se que era necessário aplicar 362 formulários, considerando um erro amostral de 5\%, um nível de confiança de 95\% e o número total de domicílios particulares permanentes ocupados na região pesquisada de 6293. A equação (1) foi utilizada para o cálculo do tamanho da amostra (MIOT, 2011).

$$
\mathrm{n}=\frac{(\mathrm{Z} \alpha / 2)^{2} \cdot \mathrm{p} \cdot \mathrm{q} \cdot \mathrm{N}}{\mathrm{e}^{2} \cdot(\mathrm{N}-1)+(\mathrm{Z} \alpha / 2)^{2} \cdot \mathrm{p} \cdot \mathrm{q}}=\frac{(1,96)^{2} * 50 * 50 * 6293}{(5)^{2} *(6293-1)+(1,96)^{2} * 50 * 50}=362
$$

Onde:

$\mathrm{n}=$ tamanho da amostra

$\mathrm{N}=$ tamanho da população finita

$\mathrm{Z} \alpha 2$ = Valor crítico para o grau de confiança $\alpha$ (tabela bicaudal), usualmente 1,96 $(95 \%)$

$\mathrm{e}=$ erro amostral, usualmente $\pm 5 \%$

p.q = porcentagem pelo qual o fenômeno ocorre, sendo $\mathrm{p}$ a proporção de resultados favoráveis da variável na população e q a proporção de resultados desfavoráveis na população (q=1-p)

Após a aplicação dos formulários e coleta dos dados... 
Tabela 2. Número de formulários aplicados em cada bairro do estudo

\begin{tabular}{cc}
\hline Parque Alvorada & 70 \\
\hline Jardim Carioca & 80 \\
\hline Parque Santa Helena ou Jardim Guarus & 73 \\
\hline Parque Santo Antônio & 66 \\
\hline Parque Vicente Gonçalves Dias & 69 \\
Total & $\mathbf{3 6 2}$ \\
\hline
\end{tabular}

Os dados coletados foram tabulados a fim de facilitar a construção de gráficos e análise das informações, as quais foram comparadas às referências usadas no trabalho, possibilitando chegar a determinadas conclusões.

\section{4- Resultados}

Os resultados mostram de acordo com o Gráfico 2 que 38\% dos entrevistados gastam entre $5 \%$ e $10 \%$ da renda familiar com energia elétrica, 35\% gastam menos que 5\%, 19\% gastam entre $10 \%$ e $15 \%$, e $8 \%$ dos entrevistados gastam entre $15 \%$ e $20 \%$ da renda com as tarifas elétricas.

\section{Percentual do Rendimento Familiar Gasto com Energia Elétrica}

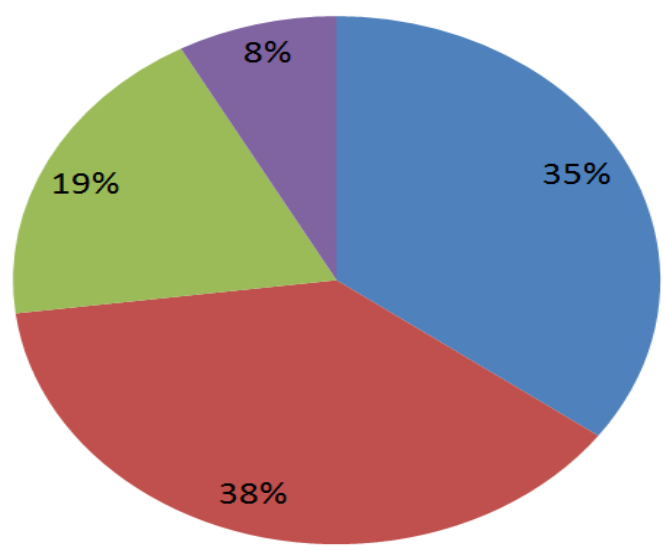

Gráfico 2 - Percentual da renda da população amostral que são gastos em contas de energia elétrica. Fonte: elaboração própria. 
Numa média geral, a pesquisa identificou que a população gasta aproximadamente $10 \%$ da renda familiar com energia elétrica. Esse resultado corrobora com o resultado obtido por Andrade (2014), que identificou que em média, 9,3\% da renda familiar é destinada ao pagamento da conta de energia elétrica.

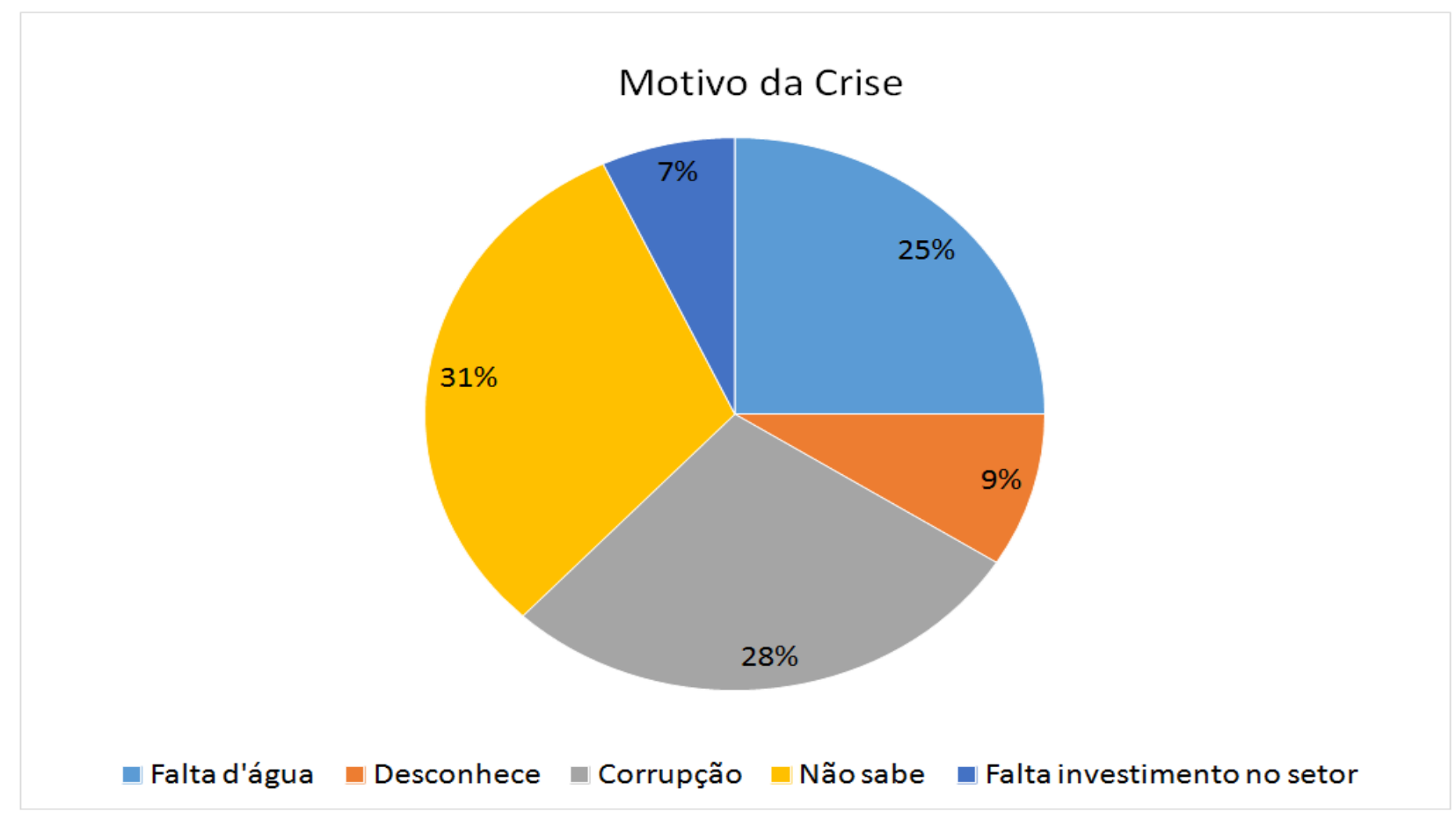

Gráfico 3 - Conhecimentos da população sobre as causas da crise energética.

Fonte: elaboração própria.

Em relação aos conhecimentos da população sobre os motivos que levaram à alta da energia elétrica, observa-se no Gráfico 3 que 31\% das pessoas não sabem dizer os motivos; $28 \%$ dos entrevistados disseram que a culpa é da corrupção no governo; $25 \%$ afirmam ser a falta d'água e $9 \%$ desconhecem a existência do aumento.

A menor porcentagem da população, $7 \%$, atribuiu a crise à falta de investimento no setor elétrico.

Quanto às medidas para diminuir os gastos com energia elétrica, a maioria dos entrevistados afirmam estar adotando medidas como manter as luzes e equipamentos desligados quando não há pessoas no ambiente, isto é, o uso de eletrodomésticos diminuiu. Além de pouparem energia, os consumidores também procuram o uso ponderado da água, já que ela é necessária para o funcionamento das hidrelétricas. 
Aproximadamente $80 \%$ da população afirmou apagar luzes e desligar aparelhos. Dentro dessa porcentagem, $23 \%$ das pessoas apagam as luzes, $7 \%$ somente desligam os aparelhos e $70 \%$ tomam ambas as medidas.

A pesquisa foi realizada em domicílios em que a renda familiar declarada pelos entrevistados encontra-se entre 1 e 3 salários mínimos.

\section{5- Conclusão}

Sabe-se que o Brasil é um país de grande extensão territorial, o que faz com que tenha regiões com bastantes diferenças entre si. Cada região possui um maior potencial a ser aproveitado, seja ele a velocidade do vento, a incidência solar ou mesmo a força das marés, já que o litoral brasileiro abrange uma grande área.

Entretanto, a matriz energética brasileira continua extremamente dependente do fornecimento de energia das hidrelétricas, abstendo-se de aproveitar as outras oportunidades que o território oferece. Isso faz com que num momento de crise, como o que se passou, o país tenha que lançar mão a fontes de energia elétrica com custo bem elevado de geração, o que implica diretamente na população.

Essa grande disponibilidade de condições para implementação de fontes de energia elétrica alternativas deveria ser melhor aproveitada. Desde a crise de racionamento ocorrida durante o governo do presidente Fernando Henrique Cardoso, vários projetos para a utilização de fontes energéticas além da hidráulica foram feitos por estudiosos.

Porém, apesar do Brasil possuir um uso maior dentro de sua matriz energética dessas fontes se comparado àquela época, sua representação ainda é pequena e decorre do destaque das questões ambientais mundialmente, que tem feito os países buscarem fontes de energia elétrica limpas. Assim, o Brasil tem uma matriz considerada limpa, até mesmo se comparada às matrizes energéticas de outros países em desenvolvimento.

Visto isso, nota-se que o que levou o país a esse momento de crise foi basicamente a falta de planejamento e de investimentos em outras fontes de energia, em acordo com Kirchner (2015), já que o próprio crescimento populacional torna necessário investir numa oferta maior de energia, de modo que ela consiga suprir a demanda.

Uma solução para resolver essa crise energética foi o aumento das tarifas de eletricidade, deixando a população insatisfeita, pois a maioria não sabe a que se deve essa cobrança. Além disso, boa parte do salário dos consumidores residenciais têm sido destinados somente ao pagamento das contas de luz. 
Com isso, a população começou a tomar medidas para economizar energia, mostrando que os métodos para cobrança de um uso maior de energia foram eficientes na medida que os consumidores diminuíram seus consumos e passaram a ter mais preocupação em economizar energia elétrica, até mesmo em utilizar equipamentos com maior eficiência energética.

Dessa forma, surge o questionamento sobre o conhecimento dos consumidores acerca do real motivo pelo qual o Brasil precisa atravessar esse momento de crise energética. Através da análise dos resultados obtidos, é possível notar que 31\% dos entrevistados não souberam responder sobre as razões da crise. Por outro lado, 28\% atribui o problema à corrupção e $25 \%$ a falta d'água, mostrando que a população tem buscado conhecimento a respeito das dificuldades passadas no país.

O problema da corrupção tem afetado todo o país, sendo manchete em jornais de diversos países, e realmente, pode-se aqui afirmar que a população tem razão ao apontar este fator de forma tão expressiva, podendo ainda associar a este, o problema da má administração que levou a construção de usinas termelétricas para geração de energia, na tentativa de resolver emergencialmente os problemas da crise no início dos anos 2000, sendo questionável esse investimento.

Um assunto tão importante como este para a sociedade num contexto geral, não pode ficar distante do debate popular, haja visto, que as ações que da população são importantíssimas, tanto no que diz respeito a energia elétrica, quanto no que tange ao desperdício de água. Grande parte da população ainda tem pouca conscientização quanto a utilização de recursos naturais, conforme comentado anteriormente, isso faz com que o consumo de energia e de água aumente, causando uma desproporcionalidade entre consumo e geração.

Uma medida que poderia ser tomada é ampliar as políticas de conservação de energia, não somente em períodos de crise. Além disso, seria importante o investimento em novas fontes energéticas e a maior publicidade por parte do governo sobre o que diz respeito ao setor energético.

De acordo com Goldemberg (2015), o indispensável para aumentar os investimentos nesse setor é uma mudança em relação aos leilões e definição de normas para o mesmo, na busca de tornar o setor mais disputado comercialmente.

Assim, é possível notar que o problema da falta de água que tem levado o país a crises no setor de energia elétrica, não é um problema causado unicamente pela falta de chuvas, mas também uma questão social cultural, administrativo por parte do poder público e empresas privadas responsáveis pelos recursos hídricos e energéticos do país. 


\section{6-Referencias Bibliográficas}

ACHÃO, C. da C. L. Análise de estrutura de consumo de energia pelo setor residencial brasileiro. Dissertação (Mestrado em Ciências - Planejamento Energético) - COPPE/UFRJ. Rio de Janeiro: 2003.

AFONSO, G. S. Análise dos Instrumentos Normativos de Suporte à Geração Solar Fotovoltaica Distribuída Conectada à Rede de Distribuição. 2012. 146 p. Dissertação (Mestrado em Engenharia Elétrica, Publicação PPGENE.DM - 489/2012) - Departamento de Engenharia Elétrica, Universidade de Brasília, Brasília, DF. Disponível em: <http://repositorio.unb.br/bitstream/10482/12051/1/2012_GeraldoSidneiAfonso.pdf $>$. Acessado em: abr. 2016.

ANDRADE, F. V. Projeções e avaliação do consumo de energia elétrica para o setor residencial brasileiro a partir da técnica de decomposição Logarithmic Mean Divisia Index (LMDI). 2014. 155p. Tese (Ciências e Técnicas Nucleares) - Universidade Federal de Minas Gerais, Escola de Engenharia, Minas Gerais.

ANEEL - Agencia Nacional de Energia Elétrica. Atlas de Energia Elétrica - $1^{\underline{a}}$ ed., Brasília, 2002. Disponível em: <http://www2.aneel.gov.br/arquivos/pdf/ livro_atlas.pdf>. Acessado em: abr. 2016.

BARDELIN, C. E. A. Os efeitos do Racionamento de Energia Elétrica ocorrido no Brasil em 2001 e 2002 com ênfase no Consumo de Energia Elétrica. 2004. 113 p. Dissertação (Mestrado em Engenharia) - Escola Politécnica da Universidade de São Paulo, São Paulo.

BRASIL. Câmara dos deputados, Rádio Câmara. Crise hídrica: falta d'água chega ao Sudeste; como tudo começou? - Bloco 1. Brasília, DF, 2015. Disponível em: < http://www2.camara.leg.br/camaranoticias/radio/materias/REPORTAGEMESPECIAL/481135-CRISE-HIDRICA-FALTA-D\%E2\%80\%99AGUA-CHEGA-AOSUDESTE-COMO-TUDO-COMECOU---BLOCO-1.html>. Acessado em: out. 2016.

BRASIL. Decreto no 5025, de 30 de março de 2004. Programa de Incentivo às Fontes Alternativas de Energia Elétrica - PROINFA. Diário Oficial, 31 mar. 2004. 
BRASIL. Ministério de Minas e Energia. Empresa de Pesquisa Energética. Balanço Energético Nacional: séries completas (2002-2011). Rio de Janeiro: EPE, 2012. Disponível em: <https://ben.epe.gov.br/BENSeriesCompletas.aspx>. Acessado em: out. 2015.

BRASIL. Ministério de Minas e Energia. Empresa de Pesquisa Energética. Balanço Energético Nacional 2014: ano base 2013. Relatório Final. Rio de Janeiro: EPE, 2014. 282p. Disponível em: <https://ben.epe.gov.br/downloads/Relatorio_Final_BEN_2014.pdf>. Acessado em: abr. 2016.

BRASIL. Ministério de Minas e Energia. Empresa de Pesquisa Energética. Balanço Energético Nacional 2015: ano base 2014. Relatório Final. Rio de Janeiro: EPE, 2015. 282p. Disponível em: < https://ben.epe.gov.br/downloads/Relatorio_Final_BEN_2015 .pdf>. Acessado em: abr. 2016.

BRASIL. Ministério de Minas e Energia. Resenha Energética Brasileira. Brasília, junho de 2015. Disponível em <http://www.mme.gov.br/documents/1138787/1732840/ Resenha+Energ\%C3\%A9tica+-+Brasil+2015.pdf/4e6b9a34-6b2e-48fa-9ef8-dc70084 70bf2>. Acessado em: abr. 2016.

BRASIL. Ministério do Planejamento, Orçamento e Gestão. Instituto Brasileiro de Geografia e Estatística. Informações sobre bairros segundo os municípios. Disponivel em: <www.ibge.gov.br/home/presidencia/noticias/imprensa/ppts/0000000486.xls>. Acessado em: mar. 2017.

BRASIL Portal Brasil. Carvão Mineral. Brasília/DF, 2011. Disponível em: <http://www.brasil.gov.br/infraestrutura/2011/11/carvao-mineral>. Acessado em: mar. 2017.

BRASIL. Portal Brasil. Energia renovável representa mais de $42 \%$ da matriz energética brasileira. Brasília/DF, 2015. Disponível em: <http://www.brasil.gov.br/meioambiente/2015/11/energia-renovavel-representa-mais-de-42-da-matriz-energeticabrasileira>. Acessado em: abr. 2016.

BRASIL. Portal Brasil. Matriz energética. Brasília/DF, 2010. Disponível em: <http://www.brasil.gov.br/meio-ambiente/2010/11/matriz-energetica>. Acessado em: abr. 2016. 
BRONZATTI, F. L.; IAROZINSKI NETO, A. Matrizes Energéticas no Brasil: cenário 20102030. Revista Brasileira de Energia, Rio de Janeiro, 2008, n. 1, v. 13. Disponível em: <http://new.sbpe.org.br/wp-content/themes/sbpe/img/artigos_pdf/v13n01/v13 n01a1.pdf>. Acessado em: abr. 2016.

CASTANHEIRA, Nelson Pereira. Introdução à Estatística. In: CASTANHEIRA, Nelson Pereira. Estatística aplicada a todos os níveis. 4. ed. Curitiba: Ibpex, 2008. Cap. 1. p. 11-20.

CRUZ, J. L. C. A eletricidade no Brasil do Império à República de Hoje. Edição: Sindicato dos eletricitários de Furnas e DME- SINDEFURNAS. São Paulo: 1994.

EBC, Empresa Brasil de Comunicação. Agência Brasil. Brasília, 2015. Disponível em: <http://agenciabrasil.ebc.com.br/geral/noticia/2015-03/mesmo-com-chuvas-situacao-dereservatorios-do-sudeste-e-critica>. Acessado em: nov. 2016.

EPE. Plano Nacional de Energia 2030. Brasília, 2007. Disponível em: <http://www.epe.gov.br/PNE/20080512_3.pdf>. Acessado em: abr. 2016.

EXAME. Crise econômica vai ficar pior, avalia Mendonça de Barros. 2015. Disponível em: $<$ http://exame.abril.com.br/economia/crise-economica-vai-ficar-pior-avalia-mendonca-debarros/>. Acessado em: nov. 2016.

GOLDEMBERG, J. O estado atual do setor elétrico brasileiro. Revista USP, São Paulo, 2015, p. 37-44, n. 104, jan./fev./mar. 2015.

GOMES, J. P. P.; VIEIRA, M. M. F. O campo da energia elétrica no Brasil de 1880 a 2002. Revista de Administração Pública, Rio de Janeiro, 2009, n. 2, v. 43, mar./abr. 2009. Disponível em: <http://www.scielo.br/pdf/rap/v43n2/v43n2a02.pdf >. Acessado em: abr. 2016.

GUIMARÃES, F. L. A crise da energia elétrica e o seu custo. Revistausp, São Paulo, v. 104, n. 1, p.83-90. Acessado em: mar. 2015.

LORENZO, Helena Carvalho de. O SETOR ELÉTRICO BRASILEIRO:: passado e futuro. Perspectivas, São Paulo, 24-25, p.147-170, 2001-2002. Disponível em: <seer.fclar.unesp.br/perspectivas/article/download/406/291>. Acessado em: mar. 2017. 
MARENGO, José A., Mudanças climatológicas e recursos hídricos. Disponível em: http://www.abc.org.br/IMG/pdf/doc-818.pdf. Acessaado em: ago. 2014.

MCGINNIS, R. L.; ELIMELECH, M. Global Challenges in Energy and Water Supply: The Promise of Engineered Osmosis. Environmental Science E Technology, Pennsylvania, v. 42, n. 23, p.8625-8629, 2008. Acessado em: mar. 2017.

MORAIS, L. C. Estudo sobre o panorama da energia elétrica no brasil e tendências futuras. 2015. 136 f. Dissertação (Mestrado) - Curso de Engenharia Elétrica, Faculdade de Engenharia de Bauru/unesp, Bauru, $2015 . \quad$ Disponível em: <http://repositorio.unesp.br/bitstream/handle/11449/132645/000852309.pdf?sequence=1 $>$. Acessado em: 12 nov. 2016.

NEHER, Clarissa. Termelétricas pesam no bolso do consumidor brasileiro. 2015. Disponível em: <http://www.dw.com/pt-br/termelétricas-pesam-no-bolso-do-consumidorbrasileiro/a-18236852>. Acessado em: abr. 2017.

O GLOBO. Entenda a crise no Cantareira: Sistema de represas em SP passa por seca recorde. Governo pede economia e descarta racionamento.. 2014. Disponível em: <http://g1.globo.com/sao-paulo/noticia/2014/07/entenda-crise-no-cantareira.html>. Acessado em: 02 nov. 2016.

RIO DE JANEIRO. Coordenação Paulo Brandi de Barros Cachapuz. Centro da Memória da Eletricidade no Brasil. Usinas da Cemig: A história da eletricidade em Minas e no Brasil de 1952-2005. 2006. 304 p. Disponível em: <https:/www.cemig.com.br/ptbr/a_cemig/nossos_negocios/usinas/Documents/livro_usinas.pdf>. Acessado em: mar. 2017.

RODRIGUES, M. F. B. Análise da atratividade econômica da microgeração minigeração distribuída no Brasil pela geração solar fotovoltaica. 2013. 79 p. Monografia (Engenharia de Energia) - Universidade de Brasília, Distrito Federal. Disponível em: $\quad$ http://bdm.unb.br/bitstream/10483/6940/1/2013_MarianaFonteBoaRodrigues.pdf $>$. Acessado em: abr. 2016.

Sistema de Estimativa de Emissões de Gases de Efeito Estufa, Observatório do Clima. Brasil vive extremos de calor em 2015. 2015. Disponível em: <http://www.observatoriodoclima.eco.br/brasil-vive-extremos-de-calor-em-2015/>. Acessado em: nov. 2016. 
TAVARES, M. A. M. E.; TAVARES, S. R. L. Perspectivas para a participação do Brasil no mercado internacional de pellets. Revista Holos, Rio Grande do Norte, 2015, ISSN 18071600. Acessado em: abr. 2016.

TELES, Lília. Baixo nível dos reservatórios prejudica parte das indústrias do RJ. O Globo: Jornal Hoje. Rio de Janeiro, jan. 2015. Disponível em: <http:/g1.globo.com/jornalhoje/noticia/2015/01/baixo-nivel-dos-reservatorios-prejudica-parte-das-industrias-dorj.html>. Acesso em: nov. 2016.

TOLMASQUIM, M. T.; GUERREIRO, A.; GORINI, R. Visão Prospectiva da Matriz Energética Brasileira: Energizando o desenvolvimento sustentável do país. Revista Brasileira de Energia, Rio de Janeiro, 2007, n. 1, v. 13. Disponível em: <http://new.sbpe.org.br/wpcontent/themes/sbpe/img/artigos_pdf/v13n01/v13n01a1.pdf>. Acessado em: abr. 2016.

TOLMASQUIM, Mauricio. As origens da crise energética brasileira. Ambiente E Sociedade, [s.1.], n. 6-7, p.179-183, jun. 2000. FapUNIFESP (SciELO).

URURAU. Há 129 anos, Campos tornava-se a pioneira em luz elétrica na América. Disponível em: <http://ururau.com.br/cidades19084>. Acesso em: 12 nov. 2016.

VICHI, Flavio Maron; MANSOR, Maria Teresa Castilho. Energia, meio ambiente e economia: o Brasil no contexto mundial. Química Nova, São Paulo, v. 32, n. 3, p.757-767, 2009. Biblioteca Digital da Produção Intelectual - BDPI, Universidade de São Paulo. Disponível em:

<http://www.producao.usp.br/bitstream/handle/BDPI/12309/art_VICHI_Energia_meio_am biente_e_economia_o_Brasil_2009.pdf?sequence=1\&isAllowed=y>. Acessado em: mar. 2017. 